\title{
O que pensam os futuros Professores de Matemática sobre o programa de bolsas de iniciação à docência
}

DOI 10.23864/cpp-v2-n1-154

Marcos Pavani Carvalho

Liliane Martinez Antonow

José Fernandes Silva

\section{Resumo}

Este artigo apresenta resultados parciais de uma pesquisa de doutorado em Educação Matemática que envolveu um grupo de cinco estudantes da Licenciatura em Matemática ingressantes no Programa de Bolsas de Iniciação à Docência - Pibid, projeto financiado pela Coordenação de Aperfeiçoamento de Pessoal de Nível Superior - Capes. Seu objetivo é discutir as percepções dos futuros professores a respeito das contribuições do Pibid no processo de desenvolvimento do conhecimento profissional. A análise de dados fundamentou-se nos estudos de Ponte $(1995$; 1998) e Ball, Thames e Phelps (2008). A coleta de dados se deu por meio de entrevistas semiestruturadas realizadas com cinco estudantes da Licenciatura em Matemática participantes do Pibid, após seis meses da inserção do grupo de futuros professores no contexto escolar. Percebemos que os futuros professores acreditam que o Pibid pode contribuir na melhoria da formação acadêmica. Constatamos indícios da articulação dos conhecimentos mobilizados nas disciplinas cursadas na licenciatura com a prática desenvolvida nas aulas ministradas. Percebemos também que a coordenação do programa não promove espaço para a reflexão acerca do planejamento e da prática realizada nas aulas ministradas pelos futuros professores. Assim, existe a necessidade de que a coordenação do Pibid - Matemática, desenvolva processos formativos para o professor da escola pública que acompanha os estudantes nas ações na escola parceira e providencie espaços para a reflexão desses docentes juntos aos futuros professores durante todo o decorrer do Pibid - para o planejamento, no decorrer e na avaliação das aulas nas escolas que integram esse projeto.

Palavras-chave: Ensino de Matemática. Formação de professores. Iniciação à Docência. 


\title{
What do future mathematics teachers think about the program for scholarships for teaching initiation
}

DOI 10.23864/cpp-v2-n1-154

\author{
Marcos Pavani Carvalho
}

Liliane Martinez Antonow

José Fernandes Silva

\section{Abstract}

This paper presents partial results of a doctorate research in Mathematical education that happened with a group of five students of Mathematics teacher training that entered in Pibid (Program for Scholarships for Teaching Initiation), program funded by Capes (Coordination of Improvement of Higher Level Personnel). The goal of this paper is to discuss perceptions of the future teachers about Pibid contributions in the process of the development of professional knowledge. The data analysis was based on studies by Ponte $(1995 ; 1998)$ and Ball, Thames and Phelps (2008). The data collection happened through semi-structured interviews with the aforementioned five students of Mathematics teacher training that entered in Pibid. After six months of the insertion of the future teachers in the scholar context, we could notice that they believed that Pibid could contribute in the improvement of academic formation. We could see evidence of an articulation of the mobilized knowledge in the teacher training courses with the practice developed in the classes taught by them. We could also see that the program coordination didn't provide spaces for reflection about the planning and practice that took place in the classes taught by the future teachers. For this matter, it is necessary that Pibid Mathematics coordination develop formative processes aiming the public education teacher that follows the Mathematics teacher training students in the actions in the partner school. It is also necessary to promote situations that enable reflection between the public school teachers and the future teachers for the planning and evaluation of actions that take place in these schools.Key-words: Mathematics teaching. Teacher training. Teaching initiation 


\section{Introdução}

O Programa Institucional de Bolsa de Iniciação à Docência - Pibid - é um programa de incentivo e valorização do magistério e de aprimoramento do processo de formação de docentes para a educação básica. Foi instituído pela Portaria Normativa no $n^{\circ}$ de 12 de dezembro de 2007, ação conjunta do Ministério da Educação, da Coordenação de Aperfeiçoamento de Pessoal de Nível Superior - Capes e do Fundo Nacional de Desenvolvimento da Educação - FNDE.

Esse Programa tem por finalidade promover a inserção dos estudantes da licenciatura no contexto das escolas públicas de Educação Básica desde o início da sua formação acadêmica para que desenvolvam atividades pedagógicas sob a orientação de um docente da licenciatura e de um professor da escola parceira. Na prática, o Programa funciona de forma a articular os diferentes atores das Instituições de Ensino Superior e Escolas Públicas da Educação Básica.

Com relação ao Pibid, Gatti; Barretto e André (2011) afirmam que:

ainda não é possível avaliar o impacto dessa política sobre as formações docentes e as próprias instituições participantes. No entanto, tem crescido o número de instituições que submetem suas propostas, conforme os editais da Capes, o que revela, no mínimo, entusiasmo por essa política, dado que as exigências são relativamente fortes. Pesquisas avaliativas sobre seus efeitos diversos poderão futuramente contribuir com conhecimentos sobre sua validade social e educacional. (GATTI, BARRETTO e ANDRÉ, 2011, p. 130).

Confirmando a importância dessa colaboração, Sacristán (2002) afirmam que:

O relacionamento entre os professores e os pesquisadores é, muitas vezes, vivido pelos professores como situação de avaliação, numa relação hierárquica: o professor formador pertence à universidade e a universidade despenca nas cabeças a hierarquia do saber (SACRISTÁN, 2002, p. 92).

Com relação ao Pibid como parceiro dos cursos de licenciatura para a formação de professores, Almeida (2015) destaca que:

Seria ingênuo pensar que a formação inicial de professores, restrita ao curso de Licenciatura, daria conta de todas as demandas da formação docente. Assim, são necessários programas de apoio, como o Pibid e o Prodocência, de forma a preencher lacunas na formação do professor, pois, reconhecidamente, as horas limitadas dos cursos de Licenciatura em Matemática, não conseguem abarcar em seu currículo disciplinas para o desenvolvimento dos conhecimentos necessários à docência (ALMEIDA, 2015, p. 139).

Nesse sentido, Moreira e David (2007) ressalta a importância de conexões entre a prática docente, a formação e a Matemática Escolar:

A nosso ver, uma questão fundamental no contexto da análise das conexões entre prática docente, a formação na licenciatura e a Matemática Escolar é a seguinte: a prática produz saberes; ela produz, além disso, uma referência com base na qual se processa uma seleção, uma filtragem ou uma adaptação dos 
saberes adquiridos fora dela, de modo a torná-los úteis ou utilizáveis (MOREIRA; DAVID, 2007, p. 42).

Percebemos que o Pibid é um campo favorável para pesquisas relacionadas à formação de professores que ensinam Matemática.

\section{A pesquisa}

O propósito desse estudo foi de investigar as percepções de cinco futuros professores a respeito do desenvolvimento das ações no Pibid. Para tanto, pretende-se responder a seguinte questão de pesquisa: Quais são as percepções dos futuros professores participantes do Pibid a respeito das ações desenvolvidas no âmbito desse programa?

O estudo aqui apresentado se justifica pelo fato de investigar questões pertinentes a formação de futuros professores de Matemática para a Educação Básica e pela identificação de carência de pesquisas no Pibid relacionadas ao processo de formação desse profissional.

A coleta de dados se deu por meio de entrevistas semiestruturadas realizadas com cinco estudantes da licenciatura participantes do Pibid.

Para a realização desse trabalho, procurou-se analisar as entrevistas com o grupo de futuros professores, tendo como objetivo identificar as percepções a respeito do desenvolvimento das ações no Pibid. A coleta dos dados foi realizada no primeiro semestre de 2015, cerca de seis meses após a inserção dos estudantes da licenciatura no contexto da escola pública.

A análise dos dados colhidos por meio das entrevistas é entendida a partir da definição proposta por Bardin (2009).

Um conjunto de técnicas de análise das comunicações visando obter por procedimentos sistemáticos e objetivos de descrição do conteúdo das mensagens indicadores (quantitativos ou não) que permitam a inferência de conhecimentos relativos às condições de produção/recepção (variáveis inferidas) destas mensagens (BARDIN, 2009, p. 44).

Nossa pesquisa, pelos objetivos propostos e questões norteadoras, é qualitativa. Neste sentido, nos balizamos em Garnica (2004) que caracteriza a pesquisa qualitativa como aquela que tem as características:

(a) a transitoriedade de seus resultados; (b) a impossibilidade de uma hipótese a priori, cujo objetivo da pesquisa será comprovar ou refutar; (c) a não neutralidade do pesquisador que, no processo interpretativo, vale-se de suas perspectivas e filtros vivenciais prévios dos quais não consegue se desvencilhar; (d) que a constituição de suas compreensões dá-se não como resultado, mas numa trajetória em que essas mesmas compreensões e também os meios de obtê-las podem ser (re) configuradas; e (e) a 
impossibilidade de estabelecer regulamentações, em procedimentos sistemáticos, prévios, estáticos e generalistas (GARNICA, 2004, p. 86).

Para identificar os depoimentos expostos neste trabalho, estabelecemos as convenções: a sigla $1 \mathrm{~S} 2$, por exemplo, refere-se à $1^{\mathrm{a}}$ categoria referente à segunda unidade de contexto do professor da escola parceira, a sigla $1 \mathrm{~A} 3$ refere-se $1^{\mathrm{a}}$ categoria referente à terceira unidade de contexto do licenciando A, a sigla 2D1 refere-se à segunda categoria referente à primeira unidade de contexto do licenciando $\mathrm{D}$, e assim por diante.

\section{Marco teórico}

O subsídio teórico desta investigação está pautado nas abordagens sobre o desenvolvimento profissional do professor de Matemática segundo Ponte $(1995 ; 1998)$ e os estudos desenvolvidos por Ball, Thames e Phelps (2008). De acordo com Ponte (1995), o conceito de desenvolvimento profissional é relativamente recente sobre a formação de professores e é próxima da noção de formação. Mas não é uma noção equivalente.

Apresentamos a seguir algumas características de formação e desenvolvimento profissional proposto por Ponte (1995).

Quadro 2: Formação X Desenvolvimento profissional

\begin{tabular}{|c|c|c|}
\hline & Formação & Desenvolvimento Profissional \\
\hline  & $\begin{array}{l}\text { Está muito associado à ideia de } \\
\text { "frequentar" cursos, numa lógica mais } \\
\text { ou menos "escolar"; } \\
\text { O movimento é essencialmente de } \\
\text { fora para dentro, cabendo-lhe } \\
\text { absorver os conhecimentos e a } \\
\text { informação que lhe são transmitidos; } \\
\text { A formação atende principalmente } \\
\text { àquilo em que o professor é carente; } \\
\text { A formação tende a ser vista de modo } \\
\text { compartimentado, por assuntos ou } \\
\text { disciplinas, como na formação inicial; } \\
\text { Parte invariavelmente da teoria e } \\
\text { muitas vezes não chega a sair da } \\
\text { teoria. }\end{array}$ & $\begin{array}{l}\text { Processa-se através de múltiplas formas e } \\
\text { processos, que inclui a frequência de cursos, mas } \\
\text { também outras atividades como projetos, que inclui } \\
\text { trocas de experiências, leituras, reflexões, etc; } \\
\text { O movimento de dentro para fora, na medida em } \\
\text { que toma as decisões fundamentais relativamente } \\
\text { às questões que quer considerar, aos projetos que } \\
\text { quer empreender e ao modo como os quer executar; } \\
\text { O professor é objeto de formação, mas é sujeito no } \\
\text { desenvolvimento profissional; } \\
\text { Parte dos aspectos que o professor já tem, mas que } \\
\text { podem ser desenvolvidas; } \\
\text { Pode partir da teoria como da prática, e em } \\
\text { qualquer caso, tende a considerar a teoria e a } \\
\text { prática de forma interligada. }\end{array}$ \\
\hline
\end{tabular}

Fonte: Adaptação nossa com base nas ideias de Ponte (1995) 
Fica evidente que falar em formação e em desenvolvimento profissional não é a mesma coisa. Em relação ao desenvolvimento profissional, Ponte (1995) afirma que:

A introdução deste conceito representa uma nova perspectiva de olhar os professores. Ao se valorizar o seu desenvolvimento profissional, eles deixam de ser vistos como meros receptáculos de formação passando, pelo contrário, a ser tidos como profissionais autônomos e responsáveis com múltiplas facetas próprias. (PONTE, 1995, p. 5).

Ponte (1998), afirma que para um professor de Matemática exercer bem suas atividades profissionais, deve ter:

(a) Bons conhecimentos e uma boa relação com a Matemática;

(b) Conhecer com profundidade o currículo;

(c) Conhecer o aluno e a aprendizagem;

(d) Dominar os processos de instrução, os diversos métodos e técnicas, relacionando-os com os objetos e conteúdos curriculares;

(e) Conhecer a escola em que trabalha e o sistema educativo;

(f) Conhecer a si mesmo como profissional.

Objetivando organizar seu estudo, Ball, Thames e Phelps (2008) propõem seis subcategorias, conforme segue.

Conhecimento Comum do Conteúdo - O conhecimento comum do conteúdo refere-se a um conhecimento que não é característico apenas do professor, mas comum às profissões que valem dos conhecimentos matemáticos para desenvolver suas funções.

Conhecimento Especializado do Conteúdo - Ainda no domínio do conhecimento do conteúdo, este pode ser definido, conforme Ball, Thames e Phelps (2008), como o conhecimento do conteúdo e as competências unicamente necessárias para a condução do trabalho docente. É o tipo de conhecimento usado unicamente pelos professores. Trata-se de um conhecimento muito presente na prática do professor, pois, através dele, podem-se encontrar padrões nos erros dos alunos, obter generalizações, responder a perguntas de "Por quê?" dos alunos usando diferentes recursos, exemplificar, usar representações, estabelecer relações entre tema e assuntos de diferentes épocas, adaptar currículos, modificar tarefas, escolher e desenvolver definições e demonstrações ou incentivar o debate de questões importantes.

Conhecimento Horizontal do Conteúdo - Este tipo de conhecimento está relacionado com a visão e consciência dos professores quanto à organização do conteúdo no âmbito do currículo. Nas palavras de Ball, Thames e Phelps (2008) este conhecimento se refere à:

[...] consciência de como estão relacionados temas matemáticos sobre a extensão da Matemática incluída no currículo. Professores de primeiro grau, por exemplo, podem precisar saber como a Matemática que ensinam está relacionada com o que os alunos irão aprender no Ensino Médio, para serem capazes de definir a base matemática para o que virá depois (BALL; THAMES; PHELPS, 2008, p.403, tradução nossa).

ISSN 2526-2882 
De acordo com o citado, fica evidente que se trata de que ter este tipo de conhecimento pode ajudar na tomada de decisões para o ensino, pois o professor pode avaliar como deve apresentar um determinado conteúdo para uma classe, mediante conhecimentos sobre a abordagem este conteúdo em um ano/série subsequente.

Conhecimento de Conteúdo e de Alunos - Neste domínio, Ball, Thames e Phelps (2008) relatam que o professor deve possuir habilidades para lidar com o saber dos alunos e o saber da Matemática:

Os professores devem antecipar o que os alunos possam pensar e o que eles vão achar confuso. Ao escolher um exemplo, os professores precisam prever o que os estudantes vão achar interessante e motivador. Ao atribuir uma tarefa, os professores precisam antecipar o que os alunos possam fazer com ela e se eles vão achá-la fácil ou difícil. Os professores também devem ser capazes de ouvir e interpretar o pensamento emergente e incompleto dos estudantes, da forma que os estudantes usam e expressam a linguagem. Cada uma destas tarefas requer uma interação entre o entendimento matemático específico e familiaridade com os estudantes e seu pensamento matemático (BALL; THAMES; PHELPS, 2008, p.401, tradução nossa).

Ainda nesta perspectiva, esses autores relatam que reconhecer uma resposta errada faz parte do conhecimento comum; em contrapartida, desenvolver familiaridade com erros comuns e decidir quais dos vários erros os alunos são mais propensos a fazer são exemplos de conhecimento de conteúdo e estudantes.

Conhecimento de Conteúdo e de Ensino - Os apontamentos de Ball, Thames e Phelps (2008) para este domínio evidenciam o diálogo entre o saber matemático e o saber sobre o ensino:

\begin{abstract}
Muitas das tarefas matemáticas de ensinar requerem um conhecimento matemático da elaboração da instrução. Os professores sequenciam conteúdos específicos para instrução. Eles escolhem com quais exemplos começar e quais exemplos usar para levar o estudante mais fundo no conteúdo. Os professores avaliam as vantagens e desvantagens instrucionais de representações usadas para ensinar uma ideia específica e identificar quais métodos e procedimentos diferentes valem a pena instrucionalmente. Cada uma dessas tarefas requer a interação entre entendimento matemático específico e o entendimento de questões pedagógicas que afetam a aprendizagem do estudante (BALL; THAMES; PHELPS, 2008, p.401, tradução nossa).
\end{abstract}

Portanto, de acordo com o citado, a culminância deste entendimento entre as questões matemáticas e as questões pedagógicas seria uma sala de aula onde o professor teria discernimento para mediar discussões, selecionar, organizar ou elaborar tarefas, repensar estratégias e metodologias.

Conhecimento do Conteúdo e de Currículo - Este domínio de conhecimento corresponde ao enfoque organizacional dos programas de ensino e dos materiais didáticos para ISSN 2526-2882 
o ensino dos conteúdos particulares em um dado nível de ensino. Está vinculado com as normas institucionais que determina as decisões e ações dos docentes.

\section{Resultados e discussões}

Apresentamos a seguir uma análise dos depoimentos dos futuros professores sujeitos de nossa pesquisa. Essas entrevistas apresentaram dados importantes com relação à percepção dos estudantes das contribuições do Pibid e percepção dos estudantes das contribuições das disciplinas cursadas para atuação na educação básica.

\section{Percepção dos estudantes das contribuições do Pibid}

Não houve discordância entre os futuros professores a respeito da importância do Pibid no processo de formação acadêmica e desenvolvimento profissional. Outro ponto em que houve convergência refere-se à atuação em sala de aula, os futuros professores destacam a necessidade de ter contato com os alunos da escola durante o processo de formação acadêmica. Os trechos a seguir exemplificam esse fato.

O Pibid complementou muito minha licenciatura! A experiência de dar aulas para uma sala com vários alunos, me ajudou muito na dinâmica das apresentações dos trabalhos na própria graduação assim como nas apresentações de trabalhos realizados em outros projetos (1C2).

O Pibid foi muito importante, acho que para nós é necessário ter esse contato com os alunos, mudamos o pensamento a cada dia que passamos no instituto e na escola aonde temos o Pibid. O Pibid nos mostra como é ser professor, como atuar em sala de aula, quais as dificuldades (1D2).

O Pibid é uma grande oportunidade de experiência antes da formação universitária. Com a participação no programa pude estar diretamente ligada às questões relacionadas ao lecionar do professor, assim a contribuição vai desde a postura do professor em sala de aula até as variantes da relação professor /aluno (1E1).

Nesse sentido, corroboramos com Almeida (2015) quanto à importância do Pibid na aproximação dos futuros professores com a escola, o que diminui tensões e conflitos pessoais característicos da fase de início de carreira.

Os futuros professores atribuem ao Pibid a sua melhora com relação ao modo de se comunicarem e de expressarem em público. Os depoimentos que seguem mostram essa concepção.

Depois que entrei no Pibid melhorei a forma de expressar em público e no modo como me expressar durante explicações seja para todos os alunos ou individualmente para o que está com mais dificuldade (1B2). 
O Pibid contribuiu diretamente na minha postura, no que diz respeito à comunicação. $O$ fato de assumir uma sala de aula fez com que eu deixasse de lado um pouco do medo e o nervosismo ao falar (1C1).

Referentemente a prática, as percepções desses estudantes são variadas. O estudante A, compara o Pibid com o exame de autoescola. Nessa comparação, o Pibid seria a prova prática para saber se o estudante é um bom professor. Outro aspecto é colocado pelo estudante B, que declara que o Pibid ajudou a melhorar a didática, a ter uma visão de como é ser professor e de colocar em prática o que é visto no curso. São percepções parecidas, no entanto, o estudante A visualiza o Pibid como um teste, como algo separado da formação na licenciatura, o que pode nos levar a uma visão dicotômica. Já o estudante B visualiza o Pibid como uma extensão do curso, o que nos remete a uma visão de unidade entre o curso e o Pibid. Os depoimentos a seguir podem atestar esse fato.

[...] o Pibid te proporciona mostrar tudo o que você aprendeu no curso para os alunos, e nesse processo você vai vendo se o que te ensinam na faculdade, você realmente vai usar dentro de uma sala de aula. É igual ao exame de autoescola, você vai treina, treina, treina e faz a prova prática, para ver se você é um bom piloto. O Pibid seria a prova prática, para saber se você é um bom professor, e para saber também se é isso que você quer para sua vida. A realidade é muito diferente de tudo (1A2).

Contribuiu muito na melhoria da didática, além de dar oportunidade de ter uma visão de um professor mesmo antes de ingressar no mercado de trabalho. [...] O Pibid atua como um modo de colocar em prática aquilo que aprendemos no início do curso e também na melhoria do raciocínio lógico e na experiência adquirida aos poucos (1B1).

Outra contribuição do Pibid declarada pelos estudantes A, D e E, refere-se ao desenvolvimento profissional. Esse ponto é evidenciado nas ponderações a seguir.

O Pibid foi tudo na minha formação, tudo foi um pouco de exagero, porém foi muito importante no meu comportamento dentro e fora de sala, pois antes do Pibid ainda era um menino, pois comecei com 17 anos, querendo ou não ainda era um menino, tinha pensamentos de menino, atitudes, corpo, entre outras coisas. Com a prática dentro da sala de aula, fui vendo que eu não era mais um deles, eu não estava mais ali na cadeira, sem prestar atenção na aula. Por muitas vezes eu pensei, será que é o destino, por que eu que tanto fiz bagunça em sala de aula, agora eu estava do outro lado tentando ensinar a matéria, brigando por um pouco de atenção. Eu me lembro de que eu escrevia no final do meu caderno, todo começo de ano uma frase que era mais ou menos assim: "O professor está passando mal? Não, então ele ficará com a minha presença" (1A1).

O Pibid teve uma grande contribuição na minha vida não só como professor, mas também na minha vida pessoal, antes de entrar no curso de Matemática, eu trabalhava na área de segurança em Juiz de Fora, uma área totalmente diferente da sala de aula. Com o Pibid pude ter um contato maior com os alunos e aprender que dentro da sala de aula a calma é sua maior aliada. Como professor de Matemática percebi que um conhecimento sobre o conteúdo e seu domínio são fundamentais para uma melhor compreensão do aluno (1D1). 
Na participação do Pibid eu pude ter certeza de que realmente quero ser professora, onde o mesmo contribuiu para que eu pudesse analisar como me desenvolver profissionalmente, visando melhorias no meu perfil (1E4).

No relato do estudante A percebemos que este futuro professor não teve uma postura admirável como aluno na educação básica, que entrou jovem no curso de licenciatura e por meio do Pibid percebeu que não ocupava a posição de alunos, agora ele estava na posição de professor, buscando fazer com que os alunos entendessem a matéria e suplicando por atenção. Esse estudante relata que o Pibid proporciona a vivência e certificar do que é dito pelos professores na licenciatura, conforme atestado no depoimento a seguir: "Outra comparação também é você sonhar, pois na faculdade você escuta o professor falar como é dar aula. Aí você imagina como é dar aula. Já o Pibid te proporciona a ver, a tocar, sentir a verdadeira realidade de um professor" (1A3).

Cabe destacar ainda que alguns futuros professores afirmam que, por meio das aulas ministradas, percebem a necessidade de preparar suas aulas, que às vezes é oportuno adaptar o conteúdo que pretende ensinar de acordo com os alunos, utilizando recursos pedagógicos que favoreçam o aprendizado. Assim apresentam indícios de mobilizarem habilidades relacionadas ao Conhecimento de Conteúdo e de Alunos definido por Ball, Thames e Phelps (2008).

Com o Pibid puder ver que nem sempre é fácil chegar numa sala de aula e dar aula, temos que nos preparar, treinar e ter certeza do que estamos passando para os alunos (1D3).

Pude aprender que em muitos casos é necessário ensinar de forma diversificada buscando sempre satisfazer o perfil do aluno/turma em sua aprendizagem; há turmas em que se pode ser um pouco mais ligeiro que os alunos conseguem acompanhar e há outras turmas que é necessário mostrar o conteúdo de forma mais lenta, para que estes consigam interpretar as questões matemáticas no seu tempo de aprendizagem. Há a necessidade do uso de ferramentas suportes para o ensino/aprendizagem buscando a visualização/interpretação da Matemática, como o uso de tecnologia (os softwares). Na busca de aulas diversificadas e fuga da rotina enfrentada na sala de aula por aluno/professor (1E2).

Ainda no depoimento do estudante E, é perceptível, que o futuro professor tem a sensação de melhoria na interação com a comunidade escolar, de sentir mais preparado para o planejamento de suas aulas e demonstra motivação para continuar os estudos em um curso de pós-graduação. A fala a seguir pode atestar essa afirmação.

Ganhei estrutura para me relacionar com os alunos, com a comunidade escolar, como lidar com problemas em sala de aula, como ensinar de forma diversificada, a leitura de livros/textos de autores de acordo com a situação/conteúdo que eu estava vivenciando. Como selecionar exercícios para as listas, como me planejar para as aulas, organizar o conteúdo a ser ministrado e a postura em sala de aula. Com o Pibid passei a desejar fazer mestrado na área de educação matemática. (1E3). 
Não identificamos em nenhum dos relatos contribuições acerca das orientações recebidas pela coordenação do Pibid.

\section{Percepção dos estudantes das contribuições das disciplinas cursadas para atuação na educação básica.}

Todos os cinco futuros professores de Matemática, participantes dessa pesquisa fizeram referências às disciplinas cursadas no curso de licenciatura. Houve consenso a respeito das contribuições nas atuações em sala de aula. No entanto não percebemos convergência em disciplinas da mesma categoria de conhecimento.

Os estudantes A e E citam, principalmente, as disciplinas pedagógicas no desenvolvimento de suas aulas, como podemos observar a seguir.

Fundamentos de Geometria: nas questões de ensino da Geometria em sala de aula; Metodologias de ensino: no suporte de confecção de documentos como listas de exercícios e exposição do conteúdo em formato Power point, postura do professor em sala de aula; Modelagem Matemática: conhecimento, aprendizagem de uso de softwares; Fundamentos de Matemática Elementar: conhecimento no conteúdo de funções (3E1).

As disciplinas que melhor identifico, são as matérias pedagógicas que tentam nos passar uma forma diferente de trabalhar o conteúdo, fugindo assim da maneira cotidiana e chata que os alunos tanto falam, cheguei a usar alguns desses jogos, atividade em minhas aulas do Pibid, não foi ruim, porém diversos fatores te puxam para baixo. Alguns desses fatores, é a própria repressão que nós jovens professores sofremos dos professores velhos de casa. Muitas vezes cheguei a escutar eles com deboche, falando: Nossa que bonitinho, porém você vai ver, eles não merecem esse esforço. Outro fator seria a falta de interesse dos próprios alunos em alguns com a atividade que você demorou em fazer, que perdeu o tempo que você poderia usar com outra coisa, você gasta o tempo para fazer uma coisa que você acha que eles vão gostar, e vão aprender mais fácil, aí chega na hora o pouco caso te deixa para baixo (3A1).

Constatamos no depoimento do estudante A acima, o choque com o cotidiano da escola. De um lado, professores pessimistas e de outro, alunos desinteressados. Huberman (2013) destaca que este "choque do real" é vivido em paralelo com a "descoberta" e, é o segundo aspecto que permite aguentar o primeiro e continuar.

Os estudantes B e C citam disciplinas na categoria de Conhecimento Comum do Conteúdo:

Fundamentos de Matemática Elementar I e II: Contribuiu no ensino de Funções no $1^{\circ}$ do ensino médio e Trigonometria no $2^{\circ}$ ano; Geometria Analítica: Contribuiu no ensino da mesma disciplina no $3^{\circ}$ ano do ensino médio; Tópicos de Álgebra Elementar: contribui no ensino de P.A. e P.G. no $1^{\circ}$ ano, no ensino de Matrizes no $2^{\circ}$ ano e no ensino de Polinômios no $3^{\circ}$ ano; Fundamentos da Geometria: contribuiu no ensino de Geometria no $2^{\circ}$ ano; Psicologia da Educação: ajudou a compreender a dificuldade do aluno (3B1). 
[...] as disciplinas de Fundamentos de Matemática foram as que mais contribuíram para minha atuação nas salas de aula do ensino médio que assumi no Pibid. Por exemplo: a parte de Trigonometria foi "superficial" (posso considerar que a primeira vez que estudei Trigonometria foi nas disciplinas de Fundamentos de Matemática, já na graduação!), onde cursei o ensino médio e esta foi uma das disciplinas que eu mais trabalhei com os alunos enquanto professor no Pibid (3C1).

Além das disciplinas de Conhecimento Comum do Conteúdo, o estudante $\mathrm{D}$, cita Cálculo e Estatística como disciplinas que contribuem para ministrar suas aulas. Essas disciplinas são classificadas por nós como disciplinas que contribuem principalmente para que o futuro professor desenvolva habilidades ligadas ao Conhecimento Especializado do Conteúdo.

Convém ressaltar a influência da professora de Cálculo na dinâmica de aula do estudante B. As falas a seguir podem exemplificar essa situação.

Cálculo ajuda muito e agora que estamos vendo Estatística, para passar para os meninos a parte de moda, média, mediana ficou tudo mais fácil. Matéria de Matemática Finita também, sem contar Fundamentos I e II, é basicamente toda a matéria do segundo grau: Trigonometria, logaritmo, função. Ajuda muito. Na prova de Estatística, eu e o estudante B, levamos exercícios de estatística para os alunos e ao mesmo tempo estávamos estudando para a prova. E eles resolvem bem, é lógico que o nosso calcula uma variância e outras coisas (3D2).

Comecei a fazer Cálculo. Eu gostei muito do jeito que a professora faz. As aulas de exercícios, ela faz a lista junto com a gente e explica aqueles que não conseguimos fazer. Conseguimos entender todos, procuro fazer assim nas aulas de reforço no Pibid (3B2).

Ainda com relação às disciplinas de Conhecimento Especializado do Conteúdo, o estudante $\mathrm{C}$ relata que o Cálculo e Álgebra são muito importantes, pois, algumas propriedades, apesar de interessantes não são demonstradas nos livros didáticos e que o conhecimento transmitido por meios dessas disciplinas ajuda a fazer essas demonstrações contribuindo no processo de ensino e aprendizagem, como podemos observar a seguir.

Cálculo e Álgebra, Cálculo, pois, quando vamos mostrar gráficos de funções temos uma noção do que acontece em toda a função não somente num ponto, ficando muito mais fácil de dizer para o aluno dentro do conteúdo o que acontece com o gráfico. A Álgebra também ajuda muito em sala de aula porque alguns teoremas que vem nos livros não são demonstrados. Com esse conhecimento podemos mostrar aos alunos determinadas propriedades que vão chamando a atenção do aluno e seu interesse pela Matemática (3D1).

Convém destacar que o estudante $\mathrm{D}$, ao relatar uma situação de dificuldade que os alunos têm, revela que compartilhava com esses alunos dessa carência e que foi superada somente ao fazer a disciplina como Cálculo, conforme o relato a seguir.

Eu acho muito engraçado porque eles têm uma visão que nossa reta numérica é $1,2,3,4,-1,-1$, não tem nada ali no meio, a visão deles é essa e depois que 
nós estudamos Cálculo, não é isso. Eu também tinha essa visão, era engraçado, menino de ensino médio (3D3).

O estudante $\mathrm{C}$ relata reconhecer a importância das disciplinas voltadas para a educação no lidar com os alunos ao identificar necessidades específicas. No entanto, percebe que a cada dia surgem particularidades que variam de acordo com a turma e o conteúdo.

As disciplinas educacionais (Educação Matemática, Filosofia da Educação) da graduação forneceram ideias sobre saber reconhecer a necessidade de cada aluno e possíveis caminhos para identificar e atender as necessidades específicas encontradas em cada sala de aula. Estas disciplinas auxiliaram até certo ponto, porém percebi ao longo do tempo, que a cada dia em que entrava nas salas de aulas do ensino médio para lecionar Matemática, encontrava necessidades particulares que variavam de acordo com cada aluno e com os conteúdos (3C2).

Nesse sentido, o estudante A relata a imagem que tem das disciplinas Pedagógicas.

[...] Essas disciplinas são ótimas para a criação do professor em sala, porém essa metodologia não pode ser passada em qualquer ambiente escolar, por esses fatores e muitos outros. Eu sinto que esse tipo de aula é uma aula mentirosa, pois você sai dela sentindo que pode mudar o mundo, e na realidade não é bem assim que acontece (3A2).

Convém destacar que o licenciando A, põe em dúvida as disciplinas Pedagógicas, pois acredita que não pode aplicar esses conhecimentos em qualquer sala de aula. Essa concepção pode ter sido motivada por experiência negativa nesse processo de formação.

Não podemos esquecer que os futuros professores estão em processo de formação no curso de Licenciatura em Matemática, assim não podemos exigir todas as competências e habilidades esperadas de um professor em exercício, mas podemos esperar que o Pibid, ofereça por meios de suas ações, situações que favoreçam esse desenvolvimento, elevando, assim, a qualidade da formação inicial.

\section{Considerações}

Os resultados indicam que os futuros professores acreditam que o Pibid é um caminho favorável para a melhoria da qualidade da formação acadêmica. Destacam a importância de ter contato com os alunos da educação básica no período de formação. Constatamos também que os futuros professores atribuem ao Pibid a melhoria do modo de se comunicarem em público. No entanto, todas as contribuições estão relacionadas à atuação em sala de aula dos estudantes e a relação dos conhecimentos mobilizados com as disciplinas contempladas no curso de licenciatura, apresentando assim, certa conexão entre o que é ensinado no curso de licenciatura e a prática que desempenhavam em suas aulas, mas percebemos ausência de 
espaço para a reflexão das práticas desenvolvidas nas aulas. Pôde-se identificar ausência de orientação da coordenação do Pibid acerca de metodologias inovadoras, ao conteúdo, ao currículo e também da reflexão das práticas desenvolvidas nas aulas pelos futuros professores.

\section{Referências}

ALMEIDA, R. N. Professor de Matemática em Início de Carreira: Contribuições do Pibid. Tese de Doutorado em Educação Matemática - Universidade Anhanguera de São Paulo, São Paulo, 2015.

BALL, D. L.; THAMES, M. H.; PHELPS, G. "Content Knowledge for Teaching: what makes it special?” In: Journal of Teacher Education. v. 59, n.5, novembro, p. 389-407, 2008.

BARDIN, L. “Análise de Conteúdo”. Edições 70 ed. Lisboa, 2009.

BRASIL. Capes. Portaria Normativa $n^{o} .38$ de 12 de dezembro de 2007. Dispõe sobre o Programa de Bolsa Institucional de Iniciação à Docência - PIBID. Diário Oficial da União, Brasília, DF, 13 de dezembro de 2007.

GARNICA, A. V. M. História Oral e educação Matemática. In: BORBA, M. C.; ARAÚJO, J. L. (Org.) Pesquisa Qualitativa em Educação Matemática. Belo Horizonte: Autêntica, 2004.

GATTI, B. A.; BARRETTO, E. S. S.; ANDRÉ, M. E. D. A. Políticas Docentes no Brasil. Brasília: UNESCO, 2011.

HUBERMAN, M. O ciclo de vida profissional dos professores. NÓVOA, A. (org.). Vida de Professores. Portugal. Editora: Porto, 2013.

MOREIRA, P. C.; DAVID, M. M. “A formação matemática do professor”. Belo Horizonte. Editora: Autêntica, 2007.

PONTE, J. P. Perspectivas de desenvolvimento profissional de professores de Matemática. 1995, Lisboa. Disponível em www.educ.fc.ul.pt/docentes/jponte/artigos-portemas.htm. Acesso em: 10 de abril de 2014.

PONTE, J. P. Da formação ao desenvolvimento profissional. 1998, Lisboa. Disponível em www.educ.fc.ul.pt/docentes/jponte/artigos-por-temas.htm. Acesso em: 10 de abril de 2014.

SACRISTÁN, J. G. Tendências investigativas na formação de professores. In: PIMENTA, S. G; GHEDIN, E. (orgs). Professor Reflexivo no Brasil. São Paulo. Editora: Cortez, 2002. 


\section{Biografia Resumida}

Marcos Pavani de Carvalho - Licenciatura em Matemática pela Universidade de Rio Verde, Mestrado em Matemática pela Universidade Estadual Paulista - UNESP e Doutorado em Educação Matemática pela Universidade Anhanguera de São Paulo. Professor do IF Sudeste MG - Campus Rio Pomba.

Currículo Lattes: http://lattes.cnpq.br/7751189752028275

Contato: marcos.pavani@ifsudestemg.edu.br

Liliane Martinez Antonow - Licenciatura em Matemática pela Universidade de Rio Verde e Mestrado em Matemática pela Universidade Estadual Paulista - UNESP. Professor do IF Sudeste MG - Campus Rio Pomba.

José Fernandes da Silva - Licenciatura em Matemática Universidade Estadual de Montes Claros (UNIMONTES); Licenciatura em Pedagogia - Universidade Cruzeiro do Sul (UNICSUL); Mestre em Educação - Universidade Vale do Rio Verde (UNINCOR); Doutorado em Educação Matemática - Universidade Anhanguera de São Paulo (UNIAN); Professor Instituto Federal de Minas Gerais, campus São João Evangelista (IFMG/SJE). Currículo Lattes: http://lattes.cnpq.br/3777760667525907 Contato: jose.fernandes@ifmg.edu.br 